Research Paper

\title{
Isothermal and Kinetic Evaluation of Adsorption Fish Farm Effluents by Nanocomposites (Chitosan and Activated Carbon)
}

\author{
Hassan Rezaei $^{1^{*}}$ (D), Saeedeh Rastegar ${ }^{1}$ (D), Seyyed Aliakbar Hedayati ${ }^{\text {DD }}$, Yousef Dadban Shahamat ${ }^{3}$ (D), Omid Sedaghat ${ }^{4}$ (D) \\ 1. Department of Environmental Sciences, Faculty of Fisheries and Environmental Sciences, Gorgan University of Agricultural Sciences and Natural \\ Resources, Gorgan, Iran. \\ 2. Department of Fisheries and Aquatic Ecology, Faculty of Fisheries and Environmental Sciences, Gorgan University of Agricultural Sciences and \\ Natural Resources, Gorgan, Iran. \\ 3. Department of Environmental Health Engineering, Faculty of Health, Golestan University of Medical Sciences, Gorgan, Iran. \\ 4. Department of Environmental Pollution, Faculty of Natural Resources and Marine Sciences, Tarbiat Modares University, Tehran, Iran.
}

\begin{tabular}{|c|c|}
\hline $\begin{array}{l}\text { Use your device to scan } \\
\text { and read the article online }\end{array}$ & Citation Rezaei H, Rastegar S, Hedayati SA, Dadban Shahamat Y, Sedaghat O. Isothermal and Kinetic Evaluation of Adsorp- \\
\hline 口i & tion Fish Farm Effluents by Nanocomposites (Chitosan and Activated Carbon). Journal of Advances in Environmental Health \\
\hline Fipen & Research. 2021; 9(2):129-138. http://dx.doi.org/10.32598/JAEHR.9.2.1196 \\
\hline 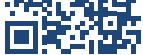 & doif: http://dx.doi.org/10.32598/JAEHR.9.2.1196 \\
\hline
\end{tabular}

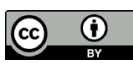

Article info:

Received: 13 Nov 2020

Accepted: 24 Feb 2021

Publish: 01 Apr 2021
Keywords:

Nano-composite, Wastewater, Chitosan, Isotherm, Kinetic

\section{A B STRACT}

Background: In wastewater treatment, removal of phosphate and ammonia is of great importance. Chitosan is a copolymer, which can be applied in low-cost adsorption. Thus, in this study, chitosan and activated carbon nanocomposite adsorbents were prepared to remove organic pollutants from the fish farm effluents.

Methods: This study was performed at different physicochemical conditions of $\mathrm{pH}$ (5-8), effluent dose (25-100 $\mathrm{mg} / \mathrm{L})$, and contact time (15-90 $\mathrm{min})$ minutes. Adsorption isotherm studies were analyzed using Freundlich, Langmuir models, and adsorption kinetics studies.

Results: The Langmuir and Freundlich isotherms for nitrite (R2=0.9076, R2=0.5911), phosphate $(\mathrm{R} 2=0.9307, \mathrm{R} 2=0.5755)$, and ammonia $(\mathrm{R} 2=0.7288$ and $\mathrm{R} 2=0.7549)$ were respectively obtained According to the results, the data of nitrite and phosphate pollutants were more consistent with the Langmuir model, but the data of ammonia pollutants were more consistent with the Freundlich. The best optimal adsorption occurred at a $\mathrm{pH}=7$. Elevation of the initial concentration of the pollutant led to the depletion of the removal functions. With increasing the contact time, adsorption efficiency increased

Conclusion: Finally, with respect to the obtained elimination percentage ( $\mathrm{R}=99.98 \%)$, chitosan and activated carbon nanocomposites have a high ability to remove organic pollutants.

\section{Introduction}

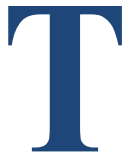

he dominant anion in aquaculture systems

is nitrogen compounds. The final product of excretion in aquaculture is ammonia, which in small quantities, causes physiological morphological disorders, and at high levels affects the fish's health., It is converted to compounds, such as nitrite and nitrate by ammonia decomposition agents $[1,2]$.

\section{${ }^{*}$ Corresponding Author:}

Hassan Rezaei, PhD.

Address: Department of Environmental Sciences, Faculty of Fisheries and Environmental Sciences, Gorgan University of Agricultural Sciences and Natural Resources, Gorgan, Iran.

Phone: +98 (911) 2807073

E-mail: hassanrezaei1979@gmail.com 
Nitrite accumulation in an aqueous environment and at optimum $\mathrm{pH}$ and temperature conditions can lead to producing more toxic compounds that have higher toxicity than nitrate. On the other hand, these two compounds and also by converting to ammonia and nitrate can cause eutrophication phenomena in aqueous environments [3]. Water used in aquaculture includes organic and mineral materials, soluble minerals, dissolved gases, suspended materials, dissolved organic compounds, and microorganisms that affect the quality of aquaculture water. Therefore, by examining the quantitative and qualitative changes in the effluent of pools and fish farming workshops and at the required time by appropriate management, the adverse environmental effects should be reduced. In order to overcome the disadvantages of physical and chemical methods, wastewater treatment is one of the methods in using the biological adsorption process on efficient wastewater treatment [4]. One of the best adsorbents for surface adsorption is using natural adsorbents. Date kernel is one of the natural organic adsorbents, which can be used as a waste of cheap agricultural wastes to remove different pollutants [5]. Chitin and Chitosan as another natural adsorbent can be named as natural adsorbent. Chitosan is a copolymer, which is prepared by the chitin of crustaceans [6]. This material is discarded as an outer covering of mollusks and crustacean's bodies and is used in various ways to remove pollutants. The advantages of adsorption with natural adsorbent are simple and easy design, no or very low sludge production, and relatively low cost compared with other methods, and regarding its reversibility, it can restore the adsorbents for other uses after adsorption using the appropriate and low-cost desorption operation. Also, the use of two adsorbents (composite) leads to the higher efficiency of the adsorbent via chemical bonding, such as covalent, ionic, van der Waals, etc. [7].

Removal of phosphate and ammonia is one of the important aspects of wastewater treatments. Phosphorus has been successfully removed from the effluent by various treatments, such as chitosan and various nanocomposites $[3,7]$. It has been known for many decades that the presence of phosphate and ammonia compounds in water can be completely injurious to the environment. Specifically, when released into the environment, phosphate and ammonia compounds can decrease the dissolved oxygen and exhibit toxicity towards aquatic life.

Today, the application of nanocomposite as an adsorbent has attracted much attention. In a study conducted by Shokouh Saljoghi et al. [8] on the adsorption to remove nitrate using modified bentonite adsorbent, the results showed that this adsorbent is a useful material for nitrate removal from aqueous solutions. Cho et al. [7] used chitosan as an absorbent. The results showed that this nanocomposite had high efficiency in nitrate and phosphate removal. In a study on the adsorption in order to remove phosphate using chitosan with titanium dioxide from an aqueous solution, the results showed that this composite was a useful adsorbent for phosphate removal from aqueous solution [3]. Thus, in this study, chitosan and activated carbon nanocomposite adsorbent were prepared to remove organic pollutants from the fish farm effluents. Regarding the research innovation, for the first time, all sorbents were used from agricultural waste (date kernels) and fish farms (shrimp shells) to use nature-friendly materials to control pollutants in the same production systems.

\section{Materials and Methods}

This study was an experimental-applied study, in which the performance of chitosan-based nanocomposites with activated carbon derived from date kernel to improve the effluent management of hydrothermal fish farms in laboratory-scale was studied. In March 2017, the effluent of hydrothermal fish farms of Aq-Qala (Golestan province, Iran) was sampled and used.

Laboratory equipment: The used devices were photometer (model 7100) to read effluent concentration, $\mathrm{pH}$ meter (8653, Taiwan) to check the $\mathrm{pH}$ value, digital scale model (Bands Bs - 3003) with an accuracy of 0.001 for weighting, Ikaks incubator shaker device (4000 IC; Germany) for mixing adsorbents and soluble pollutants, and a centrifuge (Hermle Z300; USA) with an rpm speed of 4000 to separate suspended particles from the solution.

Preparation of the absorbent: The $3 \%$ nano-chitosan

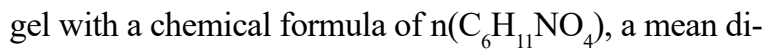
ameter of $40 \mathrm{~nm}$, grade D-acetylene 80 to $85 \mathrm{~nm}$, and a molecular weight of 5000-100000 daltons obtained by the chemical-mechanical method was prepared by the knowledge-based Novin Polymer Company. To make activated carbon, first, $200 \mathrm{~g}$ of date kernels were dried at room temperature after washing and crushed by a mill, and $20 \mathrm{~g}$ of the molded date kernels were converted to activated carbon [8].

Working method: the tests were carried out in the disjunct system and in the same condition such that at each stage, one parameter $(\mathrm{pH}$, contact time, and wastewater concentration) was variable, and other parameters were maintained. The experiment was carried out in the $\mathrm{pH}$ range of $5-8$, pollutant concentration of $25-100 \mathrm{mg} / \mathrm{g}$, and contact time of $15-90 \mathrm{~min}$. First, the suitable $\mathrm{pH}$ 
with the optimal adsorption efficiency was determined, and then, all experiments were performed at the obtained $\mathrm{pH}$. Then, the optimum wastewater concentration was determined after the system was reached to specific equilibrium mode. After obtaining optimum values of the parameters, the contact time parameter was also investigated. The experiments were carried out as follows: 100 $\mathrm{mL} / \mathrm{l}$ of effluent was poured at the desired concentration $(300 \mathrm{~mL})$, and then by adjusting the solution $\mathrm{pH}$, a certain amount of nanocomposite was added to the effluent at room temperature for a certain period on the hot plate to contact the nano-adsorbent, and the effluent was subjected to a stirring operation. Then, the solution was centrifuged for $5 \mathrm{~min}$ at $4000 \mathrm{rpm}$, and finally, the remaining wastewater concentration was read in solution with the photometer (model: 7100). The effect of each parameter in all stages of the experiment was investigated. The percentage removal of the nitrite, phosphate, and ammonia was calculated in equilibrium through Equations 1 and 2 [8-10]:

$$
\begin{aligned}
& \text { 1. } \mathrm{qe}=\frac{(\mathrm{Co}-\mathrm{Ce}) \mathrm{v}}{\mathrm{m}} \\
& \text { 2. \% Removal } \frac{\left(\mathrm{C}_{\mathrm{o}}-\mathrm{C}_{\mathrm{e}}\right) \mathrm{v}}{\mathrm{c}_{\mathrm{o}}} \times 100
\end{aligned}
$$

\section{Equilibrium model (adsorption isotherm)}

The nature of forces involved in the adsorption process was investigated using isotherm analysis. The most commonly used isotherms are the Freundlich and Langmuir isotherms. In the Langmuir isotherm, the adsorbent molecules are placed in a single layer on the adsorbent surface, and according to the Freundlich adsorption model, all energy adsorption sites are heterogeneous and multilayered [11]. The linear form of these two isotherm mod- els is presented in Table 1. To evaluating the isothermal adsorption, six different concentrations of effluent were prepared. The procedure of this experiment was that 100 $\mathrm{mL}$ of wastewater at the concentrations of $25,50,75$, and $100 \%$ were prepared from the initial solution of 1000 $\mathrm{g} / \mathrm{L}$. The optimal $\mathrm{pH}(\mathrm{pH}$ 7) for all solutions was formulated, and the amount of $1 \mathrm{~g}$ of nanocomposite was added to the solutions. Then, as in the $\mathrm{pH}$ study effect phase, the solutions were placed in a shaker and then centrifuged.

$\mathrm{N}$ indicates the Friendlich equilibrium constant that expresses the energy of bonds between metal and adsorption (intensity of adsorption), $\mathrm{kf}$ is equal to the isothermal constant of the Freundlich, which indicates the adsorption power (mg/g) (adsorption capacity), Ce is the equilibrium concentration of adsorbed ions $(\mathrm{mg} / \mathrm{L})$, and qe is the mass of the metal absorbed on the adsorbent $(\mathrm{mg} / \mathrm{g})$. In the Langmuir model, also it is assumed that the absorbent interacts only with a limited number of uniform adsorption sites, and the adsorption is confined to only one layer on the surface [12-14]. The essential characteristic of the Langmuir isotherm is shown with the aid of a constant without unit called the equilibrium parameter (RL), which is calculated using Equation 3:

$$
\text { 3. } \mathrm{RL}=\frac{1}{1+\mathrm{bCe}}
$$

$1<\mathrm{RL}$ shows undesirable isotherm, $\mathrm{RL}=1$ indicates linear isotherm, $0<\mathrm{RL}<1$ shows optimal isotherm, and $\mathrm{RL}=0$ indicates irreversible isotherm [15]. The RL equilibrium parameter is used to check the ability to use the model. Different values of the R equilibrium parameter are presented in Table 2 [14]. Ce indicates the equilibrium concentration of the adsorbed ions in $\mathrm{mg} / \mathrm{L}, \mathrm{Ce}$ indicates the equilibrium concentration of adsorbed ions

\begin{tabular}{|c|c|}
\hline Freundlich Adsorption Model & Reference \\
\hline$q=k_{f} C_{e} 1 / n$ & 3 \\
\hline $\log q_{e}=\log k_{f}+\frac{1}{n} \log C$ & 4 \\
\hline \multicolumn{2}{|l|}{ Langmuir Adsorption Models } \\
\hline$\frac{c_{e}}{q}=\frac{1}{q_{e} b}+\frac{C_{e}}{q_{e}}$ & 5 \\
\hline$q e=\frac{q_{m} \times C_{e} b}{1+C_{e} b}$ & 6 \\
\hline$\frac{C_{e}}{q_{e}}=\frac{1}{q_{m} b}+\frac{C_{e}}{q_{m}}$ & 7 \\
\hline
\end{tabular}
( $\mathrm{mg} /$ liter), qe is the mass of the metal absorbed on the

Table 1. Langmuir - freundlich adsorption model 
Table 2. Different values of RL balance parameter [12]

\begin{tabular}{cllll}
\hline $\mathbf{R}_{\mathrm{L}}>\mathbf{1}$ & $\mathbf{R}_{\mathrm{L}}=\mathbf{1}$ & $\mathbf{0}<\mathbf{R}_{\mathbf{L}}<\mathbf{1}$ & $\mathbf{R}_{\mathrm{L}}=\mathbf{0}$ & $\mathbf{R}_{\mathrm{L}}$ \\
\hline Undesirable & Linear & Optimal & Unchangeable & Isothermal type \\
\hline
\end{tabular}

adsorbent $(\mathrm{mg} / \mathrm{g})$ and the amount of pollutant absorbed, qm is the maximum adsorption capacity of $(\mathrm{mg} / \mathrm{g})$ the maximum adsorption capacity, $\mathrm{b}$ is the constant adsorption equilibrium in $\mathrm{L} / \mathrm{mg}$ (at a certain temperature) related to adsorption energy (the combination of the desired adsorbate and absorbent) (L/mg).

\section{Non-equilibrium model (kinetic adsorption)}

To investigate the kinetics of adsorption, $1000 \mathrm{ml}$ of silage solution at optimal concentration obtained from the previous steps was prepared from the parent solution. Then, the optimum $\mathrm{pH}$ was adjusted, and then in four discrete effluents, $100 \mathrm{~mL}$ of solution with the adjusted optimal $\mathrm{pH}$ was poured in each effluent, and the appropriate amount of nanocomposite obtained from the previous steps was added and placed in a shaker at . Then, we removed the ions at intervals of $15,30,60$, and 90 minutes from the shaker, and the earlier stages were repeated (Table 3). The remaining wastewater concentration was read by a spectrophotometer device (Table 4).

In Table 4, $\mathrm{q}$ and qm are the adsorption rate of effluent at time $t$ and equilibrium time, and constant $\mathrm{K}_{1}$ is the constant adsorption rate ( $1 /$ minute). Therefore, the constant $\mathrm{K}_{1}$ (1/minute) was obtained from the slope of the log (qe/ qe-q) at the time $\mathrm{t}$. In Table $2, \mathrm{~K}_{2}$ is the quasi-quadratic equation velocity constant ( $\mathrm{g} / \mathrm{mg}$ in $\mathrm{min}$ ), qe and $\mathrm{q}$ are the amounts of effluent absorbed at equilibrium $(\mathrm{mg} / \mathrm{g})$, and $\mathrm{t}$ is the time (minutes). Considering $\mathrm{t} / \mathrm{q}$ and $\mathrm{t}$, the constant value of $\mathrm{K}_{2}$ ( $\mathrm{g} / \mathrm{mg}$ in a minute), as well as qe ( $\mathrm{mg} / \mathrm{g}$ ) was calculated $[15,16]$.

\section{Data analysis}

The $\mathrm{R}$ and qe values were removed in the percentage formulas, and the equilibrium adsorption capacity and other unknown values were calculated using Excel software. To plot the curves, determine the degree of adaptation and adsorption process data with adsorption isotherm equations, and investigate the significant effect of parameters $(\mathrm{pH}$, effluent concentration, and contact time) on the adsorption rate of phosphate, nitrite, and ammonia in the aqueous solution of synthetic equations, the Past software was used.

\section{Results and Discussion}

\section{Field Emission Scanning Electron Microscopy (FE-SEM)}

The FE-SEM technique was used to investigate the morphology, appearance, particle shape, porosity, and particle size of chitosan-activated carbon nanocomposite. Figure 1 shows the dimensions of the particles (about 1-10 $\mu \mathrm{m}$ ). Pores and empty spaces (nitrite, ammonia, and phosphate) are visible.

Freundlich and Langmuir isotherms of nitrite, phosphate, and ammonia

The Langmuir and Freundlich isotherm models to remove phosphate, nitrite, and ammonia were used. Figures 2, 3, 4, 5, 6 and 7 and Table 4 indicate the linear plotting of the isothermal model of Langmuir and Freundlich. Based on the drawn shapes, the correlation coefficient

Table 3. Model of the kinetics of adsorption of nitrite, phosphate, and ammonia

\begin{tabular}{|c|c|c|}
\hline \multicolumn{2}{|c|}{ Models } & \multirow{2}{*}{$\begin{array}{c}\text { Reference } \\
9\end{array}$} \\
\hline \multirow{3}{*}{ The First-Order Kinetics } & $\frac{d q_{t}}{d_{t}}=k 1\left(q_{e}-q_{t}\right)$ & \\
\hline & $\log (q e-q t)=\log q e-\frac{K 1}{2.303} t$ & 10 \\
\hline & $\operatorname{Ln}(q e-q t)=\operatorname{Ln}(q e-k 1 . t)$ & 11 \\
\hline \multirow{2}{*}{ The Pseudo-first-order kinetics } & $\frac{d q}{d t}=k 2(q e-q t) 2$ & 12 \\
\hline & $\frac{t}{q_{t}}=\frac{1}{k_{2} q_{e}}+\frac{1}{q e} t$ & 13 \\
\hline
\end{tabular}




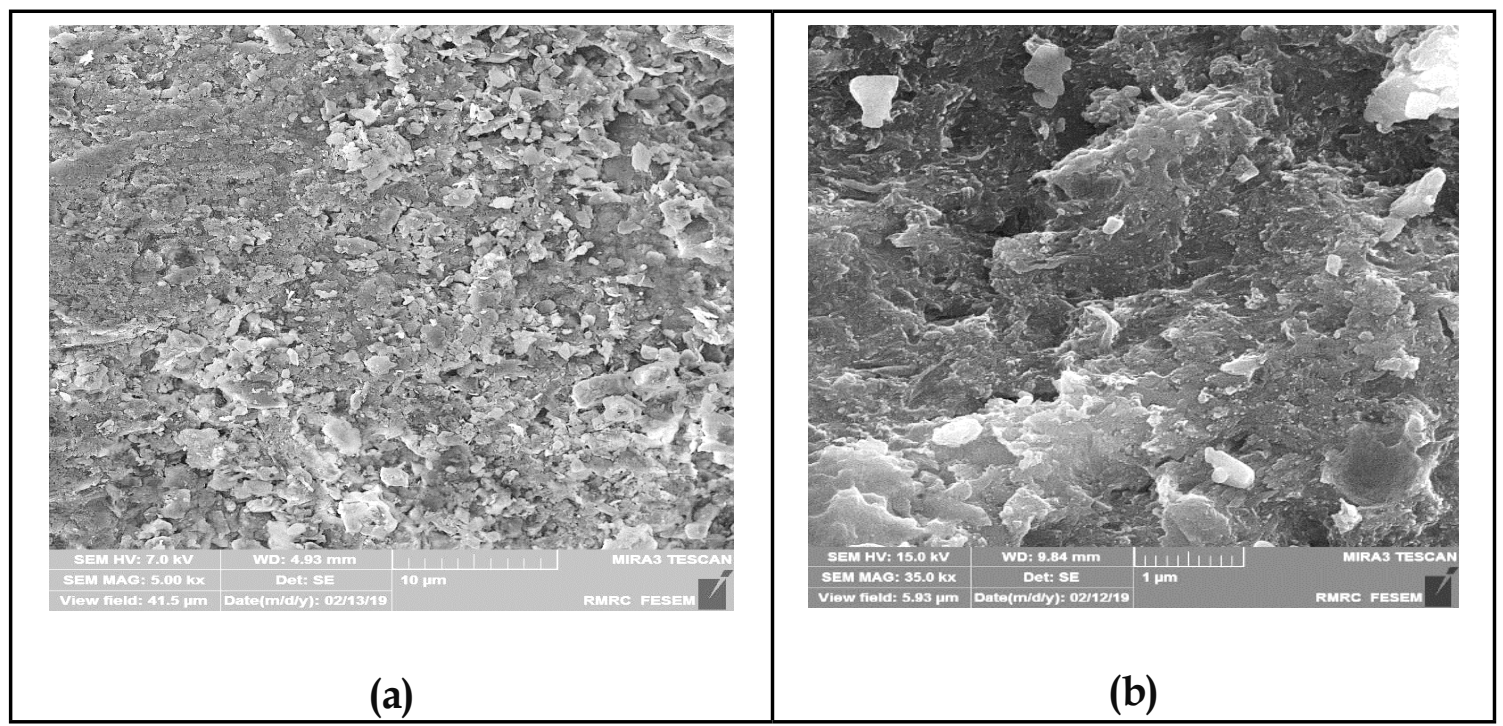

Figure 1. Electronic microscopic images of chitosan-activated carbon nanocomposite, before (a) and after (b) adsorption

of nitrite pollutants (Langmuir $\mathrm{R}^{2}=0.9076$, Frendelich $\mathrm{R}^{2}=0.5911$ ), phosphate (Langmuir $\mathrm{R}^{2}=0.9307$, Freundlich $\mathrm{R}^{2}=0.5755$ ), and ammonia (Langmuir $\mathrm{R}^{2}=0.7288$, $\mathrm{R}^{2}=0.7549$ ) was obtained.

According to the drawn shapes, the isotherms of Frendelich and Longmuir for nitrite (Langmuir $\mathrm{R}^{2}=0.9076$, Frendelich $\mathrm{R}^{2}=0.5911$ ), phosphate (Langmuir $\mathrm{R}^{2}=0.9307$, Frendelich $\mathrm{R}^{2}=0.5755$ ), and ammonia (Langmuir $\mathrm{R}^{2}=0.7288$, Frendelich $\mathrm{R}^{2}=0.7549$ ) were obtained. According to the obtained results, the data of the nitrite and phosphate pollutants were more consistent with the Langmuir model. However, the ammonia pollutant data were more consistent with the Freundlich model. Therefore, considering that the Langmuir and Freundlich models are used to describe the homoge- neous and heterogeneous surfaces of the absorber, it can be concluded that the adsorption of nitrite and phosphate pollutants was single-layer and the adsorption of ammonia pollutants was multilayer. Regarding the amount of RL that was between zero and one (Table 4), the conditions of adsorption of nitrite, ammonia, and phosphate were favorable. The $b$ values obtained regarding the adsorption with absorptive (Table 4) indicate that probably in the process of adsorption, a large number of functional groups were involved $[17,18]$.

Ekhasi et al. [19] removed the water-soluble lead metal ions using chitosan nanoparticles. Adsorption experiments were investigated in the discontinuous system and the data were more consistent with the Langmuir iso-

Table 4. Langmuir and freundlich isotherms

\begin{tabular}{|c|c|c|c|c|}
\hline \multirow{2}{*}{ Equilibrium Isotherm } & \multicolumn{3}{|c|}{ Constants } & \multirow{2}{*}{ Equilibrium Isotherm } \\
\hline & Ammonia (mg/L) & Nitrite (mg/L) & Phosphate (mg/L) & \\
\hline \multirow{4}{*}{ Langmuir } & 1.301 & 4.765 & 5.673 & $\mathrm{~b}$ \\
\hline & 3.845 & 5.473 & 3.134 & $\mathrm{q}_{\max }$ \\
\hline & 0.7288 & 0.9307 & 0.9076 & $\mathrm{R}^{2}$ \\
\hline & 0.988 & 0.148 & 0.242 & $\mathrm{RL}$ \\
\hline \multirow{3}{*}{ Freundlich } & 4.321 & 1.716 & 6.566 & $\mathrm{n}$ \\
\hline & 5.432 & 3.155 & 10.657 & $k_{f}$ \\
\hline & 0.7549 & 0.5755 & 0.5911 & $\mathrm{R}^{2}$ \\
\hline
\end{tabular}




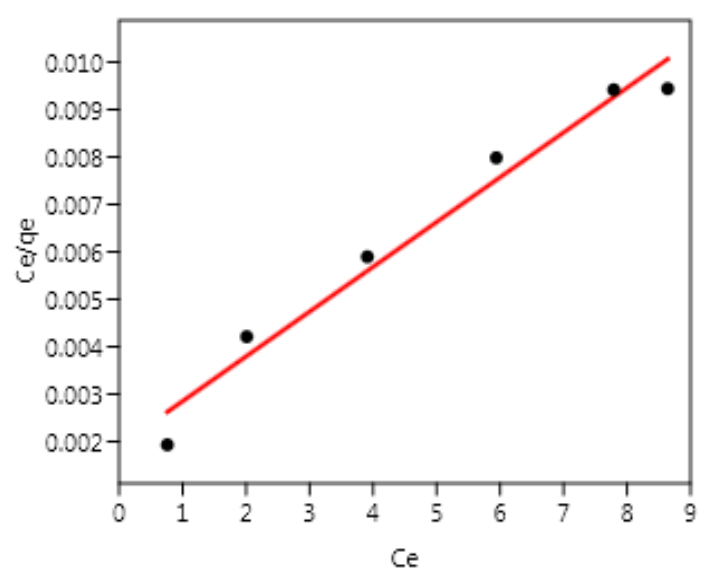

Figure 2. Langmuir adsorption isotherm for phosphate with chitosan-activated carbon nanocomposite

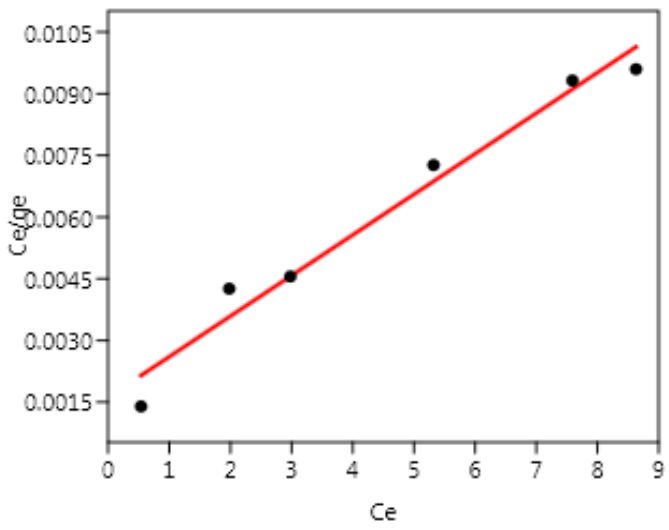

Figure 4. Langmuir adsorption isotherm for nitrite with chitosan-activated carbon nanocomposite

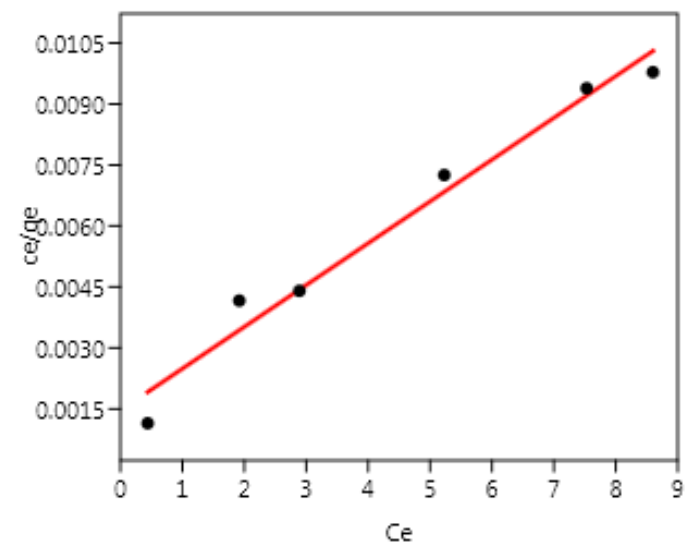

Figure 6. Langmuir adsorption isotherm for ammonia with chitosan-activated carbon nanocomposite

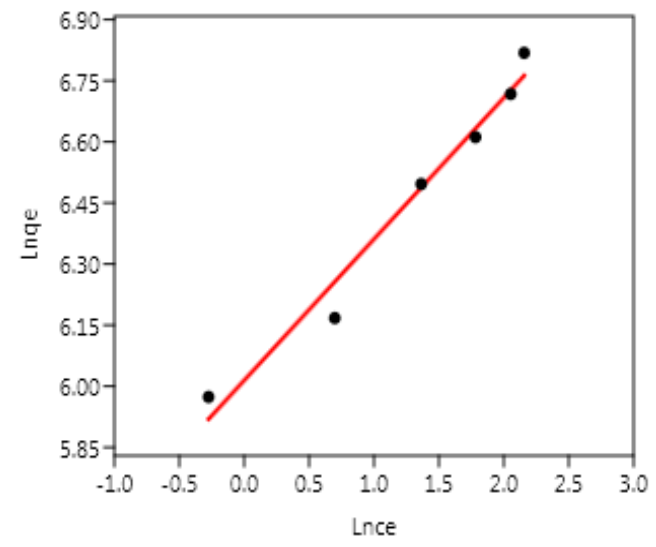

Figure. 3. Adsorption isotherm of Freundlich phosphate with chitosan-activated carbon nanocomposite

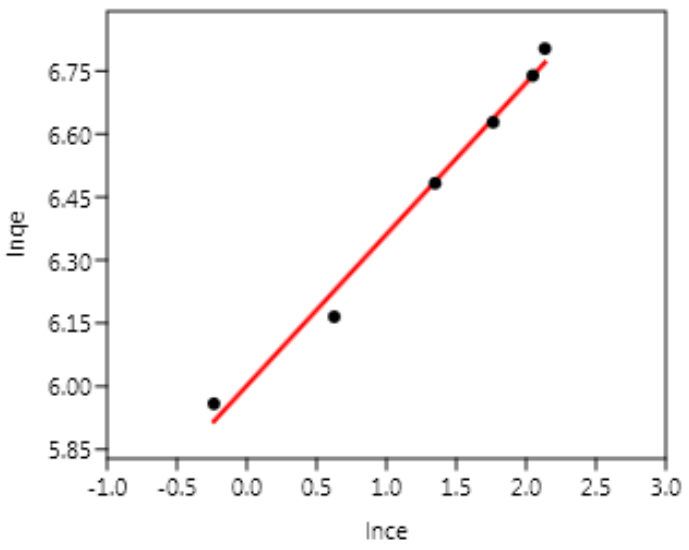

Figure 5. Adsorption isotherm of Freundlich nitrite with chitosan-activated carbon nanocomposite

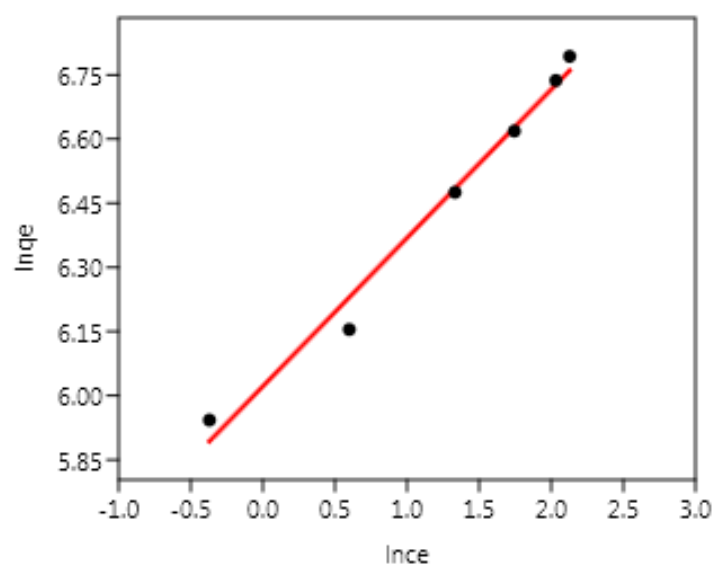

Figure 7. Adsorption isotherm of Freundlich ammonia with chitosan-activated carbon nanocomposite 


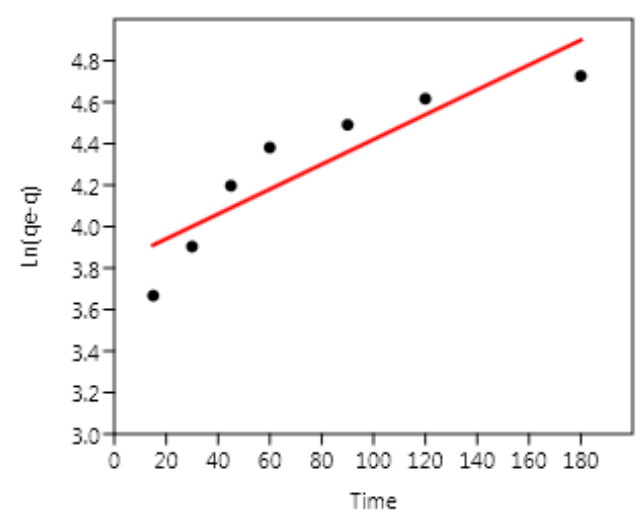

Figure 8. The pseudo-first-order kinetics of the adsorption of phosphate by chitosan-activated carbon nanocomposite

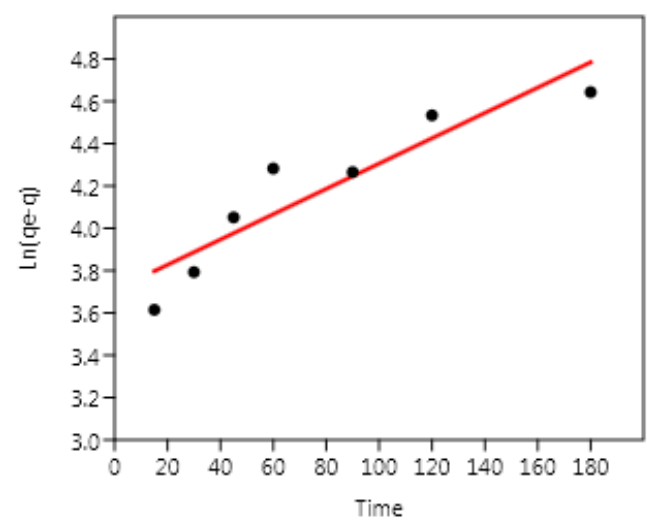

Figure 10. The Pseudo-first-order kinetics of the adsorption of nitrite by chitosan-activated carbon nanocomposite

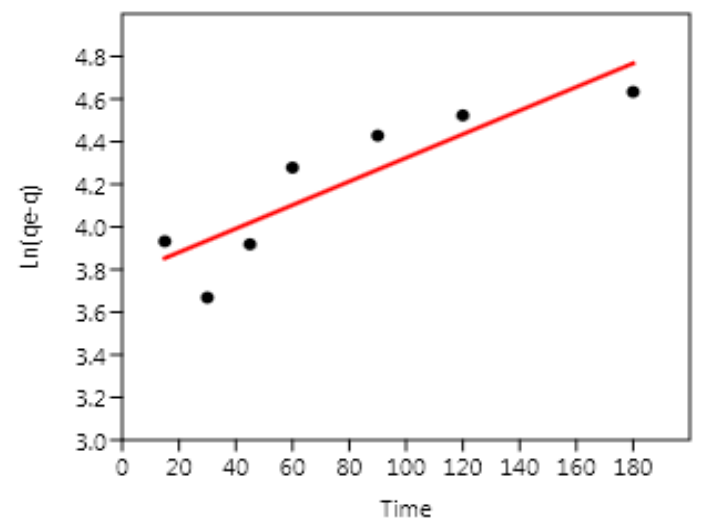

Figure 12. The pseudo-first-order kinetics of ammonia adsorption by chitosan-activated carbon nanocomposite

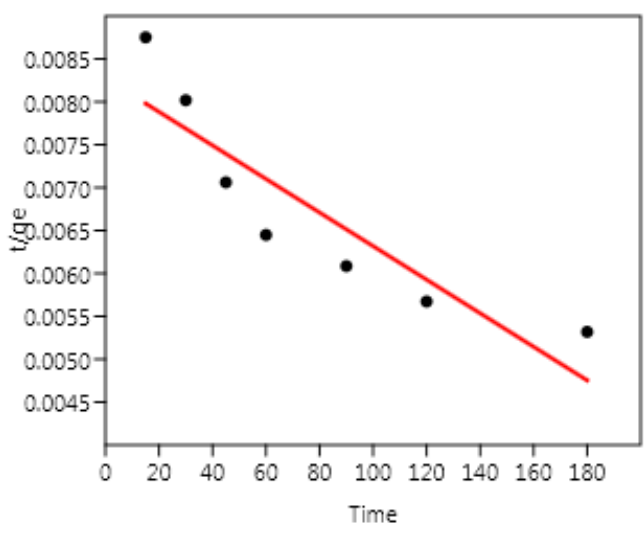

Figure 9. The pseudo-kinetics of the adsorption of phosphate by chitosan-activated carbon nanocomposite

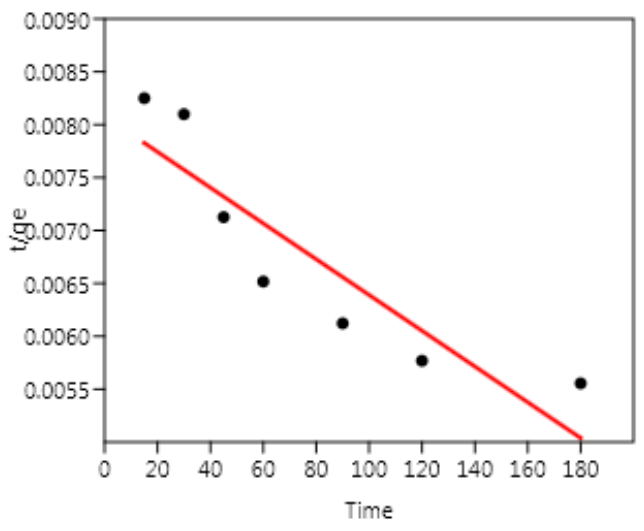

Figure 11. The Pseudo-second-order kinetics of the adsorption of nitrite by chitosan-activated carbon nanocomposite

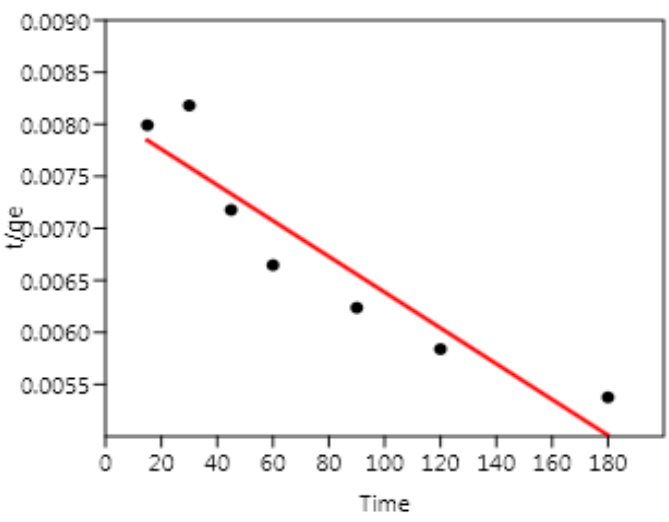

Figure 13. The pseudo-second-order kinetics of ammonia adsorption by chitosan-activated carbon nanocomposite 
Table 5. The constant kinetic coefficients

\begin{tabular}{ccccc}
\hline \multirow{2}{*}{ Adsorption Kinetics } & \multicolumn{3}{c}{ Constant } \\
\cline { 3 - 4 } & $\mathrm{k}_{1}(\mathrm{~min})$ & Ammonia & Nitrite & Phosphate \\
\hline \multirow{2}{*}{$\begin{array}{c}\text { Pseudo-first-order } \\
\text { kinetics }\end{array}$} & $\mathrm{q}_{\mathrm{exp}}(\mathrm{mg} / \mathrm{g})$ & 0.098 & 2.999 & 0.0162 \\
& $\mathrm{R}^{2}$ & 7.466 & 8.655 & 5.865 \\
& $\mathrm{~K}_{2}(\mathrm{~min})$ & 0.9976 & 0.7963 & 0.9972 \\
\hline $\begin{array}{c}\text { Pseudo-second-order } \\
\text { kinetics }\end{array}$ & $\mathrm{q}_{\mathrm{exp}}(\mathrm{mg} / \mathrm{g})$ & 0.09 & 1.86 & 0.25 \\
& $\mathrm{R}^{2}$ & 3.987 & 5.678 & 3.354 \\
\hline
\end{tabular}

therm model. Ramavandi et al. [20] investigated the performance of the active carbon produced from the date kernel in the adsorption of cyanide from synthetic wastewater. The experiment was carried out in the discontinuous system and the data were more consistent with the Langmuir isotherm model. Yousefi et al. [2] used the Mercenaria shell to remove lead from the aqueous solution. Their results showed that its kinetic and equilibrium adsorption isotherms seek the second-degree kinetics and Langmuir isotherm.

Adsorption kinetics (nitrite, ammonia, and phosphate)

To find effective factors on response rate, kinetic evaluation was carried out, and Figures 8, 9, 10, 11, 12 and 13 and Table 5 show the results of the test with pseudo-first-order and pseudo-second-order kinetic models.In this study, to predict the kinetic mechanism, pseudo-first-order and pseudo-second-order kinetic models were used. Totally, according to the obtained correlation coefficient values of the kinetics of adsorption of phosphate (pseudo-first- order $\mathrm{R}^{2}=0.9972$ ) and (pseudo-second-order $\mathrm{R}^{2}=0.8931$ ), nitrite (pseudo-first-order $\mathrm{R}^{2}=0.79633$ ) (pseudo-secondorder $\mathrm{R}^{2}=0$. 6755), and ammonia (pseudo-first-order $\mathrm{R}^{2}=0.99767$ ) and (pseudo-second-order $\mathrm{R}^{2}=0.6958$ ), the adsorption of phosphate pollutants with a pseudo-firstorder kinetic model as a controlling factor for the adsorption to the boundary layer and the changes in adsorption rate by the time was proportional to the number of nonoccupied sites at the adsorbent surface, and the adsorption of nitrite and ammonia pollutants with a pseudo-secondorder kinetic model. Zhang et al. [4] determined that the equilibrium and kinetic adsorption isotherms were more consistent with pseudo-second-order synthetic isotherm. Thirugnanasambandham et al. [21] used chitosan to purify household wastewater from chitosan and adsorption kinetics and thermodynamics were investigated. The data obtained were more consistent with the pseudo-secondorder kinetics. Dong et al. [22] removed water-soluble humic acid using magnetic chitosan nanoparticles. Adsorption kinetics and thermodynamics were investigated. The data obtained were more consistent with the pseudosecond-order kinetics (Table 6).

Table 6. Comparison of the similar studies on effluent absorbent

\begin{tabular}{cccc}
\hline Researcher & Absorbent & Pollutant & Result \\
\hline $\begin{array}{c}\text { Thirugnanasamband- } \\
\text { ham et al. }\end{array}$ & Chitosan & Household & Positive \\
Dong et al. & $\begin{array}{c}\text { Magnetic chitosan } \\
\text { nanoparticles } \\
\text { Yousefi et al. }\end{array}$ & $\begin{array}{c}\text { Water-soluble humic } \\
\text { acid }\end{array}$ & Positive \\
Ekhlasi et al. & $\begin{array}{c}\text { Chitosan nanoparticles } \\
\text { [21] }\end{array}$ & Positive \\
Ramavandi et al & $\begin{array}{c}\text { Active carbon produced } \\
\text { from the date kernel } \\
\text { Chitosan and activated } \\
\text { carbon }\end{array}$ & $\begin{array}{c}\text { Cyanide from synthetic } \\
\text { wastewater }\end{array}$ & Positive \\
Current study & $\begin{array}{c}\text { Fish farm effluents } \\
{[19]}\end{array}$ & Positive \\
\hline
\end{tabular}




\section{Conclusion}

The results showed that the use of chitosan and activated carbon nanocomposite is significantly effective in wastewater treatment of fish farms. The adsorption efficiency increased as the $\mathrm{PH}$ increased; however, the $\mathrm{pH}$ dropped more than 7. The best optimal adsorption occurred at a $\mathrm{pH}=7$. Elevation of the initial concentration of the pollutant led to the depletion of the removal functions. The results of the impact of the contact time on adsorption efficiency showed that with the increasing contact time, adsorption efficiency increases. The adsorption isotherm results showed that the adsorption data of nitrite and phosphate were more consistent with the Langmuir model, while the ammonia adsorption data were more consistent with the Freundlich model. Therefore, considering that the Langmuir and Freundlich isotherm model is used to describe the homogeneous and heterogeneous surfaces of the adsorbent, the adsorption of nitrite and phosphate pollutants was monolayer and the adsorption of ammonia was multilayer. Pseudo-first and pseudo-second-order kinetics of adsorbents was investigated for all three pollutants. Finally, with respect to the obtained elimination percentage, chitosan and activated carbon nanocomposites have are effective to remove organic pollutants.

\section{Ethical Considerations}

\section{Compliance with ethical guidelines}

All applicable international, national, and institutional guidelines for the ethical issue were followed.

\section{Funding}

This research was supported by the research project Funded by the Iran National Science Foundation (No. 96007146).

\section{Authors' contributions}

All authors participated in data collection, analysis, and interpretation, and approved the manuscript.

\section{Conflict of interest}

The authors declared no conflict of interests.

\section{References}

[1] Hayati M, Tourani S. [Experimental study on removal of mercury from aqueous solutions by using magnetite Carbon
Nanotube (CNT) as adsorbent (Persian)]. J Water Wastewater. 2019; 30(6):63-77. [DOI:10.22093/WWJ.2019.138327.2709]

[2] Yousefi Z, Mohammadpour-Tahamtan RA, MashayekhSalehi A. [The efficiency of bivalve mollusk shell in removal of lead [ $\mathrm{Pb}$ (II)] from aqueous solutions by Central Composite Design model (CCD) and optimization of effective parameters (Persian)]. J Mazandaran Univ Med Sci. 2014; 23(108):5467. http://jmums.mazums.ac.ir/article-1-2425-en.html

[3] Park KH, Kim SJ, Jeong YH, Moon HJ, Song HJ, Park YJ. Fabrication and biological properties of calcium phosphate/chitosan composite coating on titanium in modified SBF. Mater Sci Eng C. 2018; 90:113-8. [DOI:10.1016/j.msec.2018.04.060] [PMID]

[4] Zheng L, Wang Ch, Shu Y, Yan X, Li L. Utilization of diatomite/chitosan-Fe (III) composite for the removal of anionic azo dyes from wastewater: Equilibrium, kinetics and thermodynamics. Colloids Surf A Physicochem Eng Asp. 2015; 468:129-39. [DOI:10.1016/j.colsurfa.2014.12.015]

[5] Jonoobi M, Shafie M, Shirmohammadli Y, Ashori AR, Zarea-Hosseinabadi $\mathrm{H}$, Mekonnen T. A review on date palm tree: Properties, characterization and its potential applications. J Renew Mater. 2019; 7(11):1055-75. [DOI:10.32604/ jrm.2019.08188]

[6] Nouri Dodaran P, Fataei E, Khanizadeh B. [Study on photocatalytic and sonocatalytic activity of $\mathrm{Bi}_{2} \mathrm{O}_{3}$ synthesized by Sol-gel method in removing organic compounds of Ardabil textile factory effluents (Persian)]. J Water Wastewater. 2019; 30(4):67-77. [DOI:10.22093/WWJ.2018.110808.2566]

[7] Cho DW, Jeon BH, Chon CM, Schwartz FW, Jeong Y, Song $\mathrm{H}$. Magnetic chitosan composite for adsorption of cationic and anionic dyes in aqueous solution. J Ind Eng Chem. 2015; 28:60-6. [DOI:10.1016/j.jiec.2015.01.023]

[8] Shokouh Saljoghi Z, Malekpour A, Rafiee GR, Imani A, Bakhtiary M. [Removal of nitrite and nitrate from Recirculation Aquaculture System effluent (RAS) by modified bentonites (Persian)]. J Water Wastewater. 2011; 22(2):46-54. http:// www.wwjournal.ir/article_1248.html

[9] Rahimi K, Mirzaei R, Akbari A, Mirghaffari N, Yoonesnia A. [Optimization of red 46 dye removal using magnetic polymeric adsorbent prepared from polyacrilonitrile fibers (Persian)]. J Water Wastewater. 2019; 30(4):109-21. [DOI:10.22093/ WWJ.2018.113405.2585]

[10] Bozorgpour F, Fasih Ramandi H, Jafari P, Samadi S, Sharif Yazd Sh, Aliabadi M. Removal of nitrate and phosphate using chitosan $/ \mathrm{Al}_{2} \mathrm{O}_{3} / \mathrm{Fe}_{3} \mathrm{O}_{4}$ composite nanofibrous adsorbent: Comparison with chitosan $/ \mathrm{Al}_{2} \mathrm{O}_{3} / \mathrm{Fe}_{3} \mathrm{O}_{4}$ beads. Int J Biol Macromol. 2016; 93(Pt A):557-65. [DOI:10.1016/j.ijbiomac.2016.09.015] [PMID]

[11] Binaeian E, Babaee Zadvarzi S, Hoseinpour Kasgari AR, Ebrahimnezhd Afrouzi M. [In situ synthesis of chitosan-grafted polyacrylamide loaded by $\mathrm{TiO}_{2}$ nanoparticles for the adsorption of sirius yellow K-CF from aqueous media: Isotherm, kinetic and thermodynamic studies (Persian)]. J Water Wastewater. 2019; 30(5):16-30. [DOI:10.22093/WWJ.2018.134555.2694]

[12] Abdollahi Garekand J, Sepehr E, Feiziasl V, Rasouli-Sadaghiani MH,Samadi A. [Comparison of the efficiency of unmodified and chemically modified low-cost biosorbents in the removal of lead from aqueous solutions (Persian)]. J Water Wastewater. 2019; 30(5):1-15. [DOI:10.22093/WWJ.2019.121811.2644] 
[13] Zhao Y, Guo L, Shen W, An Q, Xiao Z, Wang H, et al. Function integrated chitosan-based beads with throughout sorption sites and inherent diffusion network for efficient phosphate removal. Carbohydr Polym. 2020; 230:115639. [DOI:10.1016/j. carbpol.2019.115639] [PMID]

[14] Tyagi S, Rawtani D, Khatri N, Tharmavaram M. Strategies for nitrate removal from aqueous environment using nanotechnology: A review. J Water Process Eng. 2018; 21:84-95. [DOI:10.1016/j.jwpe.2017.12.005]

[15] Mor S, Chhoden K, Negi P, Ravindra Kh. Utilization of nano-alumina and activated charcoal for phosphate removal from wastewater. Environ Nanotechnol. Monit Manag. 2017; 7:15-23. [DOI:10.1016/j.enmm.2016.11.006]

[16] Pu Sh, Deng D, Wang K, Wang M, Zhang Y, Shangguan L, et al. Optimizing the removal of nitrate from aqueous solutions via reduced graphite oxide-supported nZVI: Synthesis, characterization, kinetics, and reduction mechanism. Environ Sci Pollut Res Int. 2019; 26(4):3932-45. [DOI:10.1007/s11356-0183813-1] [PMID]

[17] Nasiri J, Motamedi E, Naghavi MR, Ghafoori M. Removal of crystal violet from water using $\beta$-cyclodextrin functionalized biogenic zero-valent iron nanoadsorbents synthesized via aqueous root extracts of Ferula persica. J Hazard Mater. 2019; 367:325-38. [DOI:10.1016/j.jhazmat.2018.12.079] [PMID]

[18] Douzandeh Ziabari P, Dehghani Ghanateghestani M. [Experimental study of removal heavy metal of arsenic from water using nano absorber iron oxide/N-isopropyl acrylamide/ chitosan (Persian)]. J Water Wastewater. 2019; 30(6):78-89. [DOI:10.22093/WWJ.2019.150721.2757]

[19] Ekhlasi L, Younesi H, Mehraban Z, Bahramifar N. [Synthesis and application of chitosan nanoparticles for removal of lead ions from aqueous solutions (Persian)]. J Water Wastewater. 2013; 24(1):10-8. http:/ /www.wwjournal.ir/article_2335.html

[20] Ramavandi B, Barikbin B, Asgari Gh, Ghaedi H. [Efficacy evaluation of activated carbon prepared from date stones in cyanide adsorption from synthetic wastewater (Persian)]. J Birjand Univ Med Sci. 2013; 19(4):399-408. http://journal. bums.ac.ir/article-1-1254-en.html

[21] Thirugnanasambandham K, Sivakumar V, Prakash Marn J, Kandasumy S. Chitosan based grey wastewater treatment--A statistical design approach. Carbohydr Polym. 2014; 99:593600. [DOI:10.1016/j.carbpol.2013.08.058] [PMID]

[22] Dong Ch, Chen W, Liu Ch. Preparation of novel magnetic chitosan nanoparticle and its application for removal of humic acid from aqueous solution. Appl Surf Sci. 2014; 292:106776. [DOI:10.1016/j.apsusc.2013.12.125] 